\title{
Hereditary breast and ovarian cancer and reproduction: an observational study on the suitability of preimplantation genetic diagnosis for both asymptomatic carriers and breast cancer survivors
}

Citation for published version (APA):

Derks - Smeets, I. A. P., de Die-Smulders, C. E. M., Mackens, S., van Golde, R., Paulussen, A. D., Dreesen, J., Tournaye, H., Verdyck, P., Tjan-Heijnen, V. C. G., Meijer-Hoogeveen, M., de Greve, J., Geraedts, J., de Rycke, M., Bonduelle, M., \& Verpoest, W. M. (2014). Hereditary breast and ovarian cancer and reproduction: an observational study on the suitability of preimplantation genetic diagnosis for both asymptomatic carriers and breast cancer survivors. Breast Cancer Research and Treatment, 145(3), 673-681. https://doi.org/10.1007/s10549-014-2951-5

Document status and date:

Published: 01/06/2014

DOI:

10.1007/s10549-014-2951-5

Document Version:

Publisher's PDF, also known as Version of record

Please check the document version of this publication:

- A submitted manuscript is the version of the article upon submission and before peer-review. There can be important differences between the submitted version and the official published version of record. People interested in the research are advised to contact the author for the final version of the publication, or visit the DOI to the publisher's website.

- The final author version and the galley proof are versions of the publication after peer review.

- The final published version features the final layout of the paper including the volume, issue and page numbers.

Link to publication

\footnotetext{
General rights rights.

- You may freely distribute the URL identifying the publication in the public portal. please follow below link for the End User Agreement:

www.umlib.nl/taverne-license

Take down policy

If you believe that this document breaches copyright please contact us at:

repository@maastrichtuniversity.nl

providing details and we will investigate your claim.
}

Copyright and moral rights for the publications made accessible in the public portal are retained by the authors and/or other copyright owners and it is a condition of accessing publications that users recognise and abide by the legal requirements associated with these

- Users may download and print one copy of any publication from the public portal for the purpose of private study or research.

- You may not further distribute the material or use it for any profit-making activity or commercial gain

If the publication is distributed under the terms of Article 25fa of the Dutch Copyright Act, indicated by the "Taverne" license above,

Download date: 26 Apr. 2023 


\section{Maastricht University}

Hereditary breast and ovarian cancer and reproduction: an observational study on the suitability of preimplantation genetic diagnosis for both asymptomatic carriers and breast cancer survivors

Inge AP Derks-Smeets, Christine EM de Die-Smulders, Shari Mackens, Ron van Golde, Aimee D Paulussen, Jos Dreesen, Herman Tournaye, Pieter Verdyck, Vivianne CG Tjan-Heijnen, Madelon Meijer-Hoogeveen, Jacques De Greve, Joep Geraedts, Martine de Rycke, Maryse Bonduelle, Willem M Verpoest

\section{Published in:}

Breast Cancer Research and Treatment June 2014, Volume 145, Issue 3, pp 673681

http://dx.doi.org/10.1007/s10549-0142951-5 


\section{Hereditary breast and ovarian cancer and reproduction: an observational study on the suitability of preimplantation genetic diagnosis for both asymptomatic carriers and breast cancer survivors}

Inge AP Derks-Smeets ${ }^{\mathrm{a}, \mathrm{b}}$, Christine EM de Die-Smulders ${ }^{\mathrm{a}, \mathrm{b}}$, Shari Mackens ${ }^{\mathrm{c}}$, Ron van Golde ${ }^{\mathrm{d}}$, Aimee D Paulussen ${ }^{\mathrm{a}, \mathrm{b}}$, Jos Dreesen ${ }^{\mathrm{a}, \mathrm{b}}$, Herman Tournaye ${ }^{\mathrm{c}}$, Pieter Verdyck ${ }^{\mathrm{e}}$, Vivianne CG Tjan-Heijnen $^{\mathrm{b}, \mathrm{f}}$, Madelon Meijer-Hoogeveen ${ }^{\mathrm{g}}$, Jacques De Greve $^{\mathrm{h}}$, Joep Geraedts ${ }^{\mathrm{a}, \mathrm{b}}$, Martine de Rycke ${ }^{\mathrm{e}}$, Maryse Bonduelle ${ }^{\mathrm{e}}$, Willem M Verpoest ${ }^{\mathrm{c}}$

${ }^{a}$ Department of Clinical Genetics, Maastricht University Medical Centre +, P.O. Box 5800, 6202 AZ Maastricht, the Netherlands

${ }^{\mathrm{b}}$ GROW - School for Oncology and Developmental Biology, Maastricht University, P.O. Box 616, 6200 MD Maastricht, the Netherlands

${ }^{\mathrm{c}}$ Centre for Reproductive Medicine, Universitair Ziekenhuis Brussel, Laarbeeklaan 101, 1090 Brussels, Belgium

${ }^{\mathrm{d}}$ Department of Obstetrics and Gynaecology, Maastricht University Medical Centre +, P.O.

Box 5800, 6202 AZ Maastricht, the Netherlands

${ }^{\mathrm{e}}$ Centre for Medical Genetics, Universitair Ziekenhuis Brussel, Laarbeeklaan 101, 1090 Brussels, Belgium

${ }^{\mathrm{f}}$ Department of Internal Medicine, division of Medical Oncology, Maastricht University Medical Centre +, P.O. Box 5800, 6202 AZ Maastricht, the Netherlands

${ }^{\mathrm{g}}$ Department of Reproductive Medicine, University Medical Centre Utrecht, P.O. Box 85500, 3508 GA Utrecht, the Netherlands

${ }^{\mathrm{h}}$ Department of Medical Oncology, Universitair Ziekenhuis Brussel, Laarbeeklaan 101, 1090 Brussels, Belgium 
Corresponding author:

C.E.M. de Die-Smulders, MD, PhD

Department of Clinical Genetics

Maastricht University Medical Centre +

P.O. Box 5800

6202 AZ Maastricht

The Netherlands

Tel: $0031-43-3877859$

Fax: $0031-43-3875800$

Email: c.dedie@mumc.nl

This manuscript contains original data, which were previously presented in part at the annual meeting of the European Society of Human Reproduction and Embryology in Istanbul, on the $2^{\text {nd }}$ of July 2012. Data were presented in an oral presentation, as well as by press release. 


\begin{abstract}
Purpose

Preimplantation genetic diagnosis (PGD) is a reproductive option for BRCA1/2 mutation carriers wishing to avoid transmission of the predisposition for hereditary breast and ovarian cancer (HBOC) to their offspring. Embryos obtained by in vitro fertilisation (IVF/ICSI) are tested for the presence of the mutation, only BRCA-negative embryos are transferred into the uterus. The suitability and outcome of PGD for HBOC is evaluated.
\end{abstract}

\title{
Methods
}

Observational cohort study on PGD treatments for HBOC carried out in two of WesternEurope's largest PGD centres from 2006 until 2012. Male carriers, asymptomatic female carriers, and breast cancer survivors were eligible. If available, PGD on embryos cryopreserved before chemotherapy was possible. Generic PGD-PCR tests were developed based on haplotyping, if necessary combined with mutation detection.

Results

70 couples underwent PGD for BRCA1/2. $42 / 71$ carriers (59.2\%) were female, six (14.3\%) of whom have had breast cancer prior to PGD. In total, 145 PGD cycles were performed. 720 embryos were tested, identifying 294 (40.8\%) as BRCA-negative. Of fresh IVF/PGD cycles, 23.9\% resulted in a clinical pregnancy. Three cycles involved PGD on embryos cryopreserved before chemotherapy; two of these women delivered a healthy child. Overall, 38 children were liveborn. Two BRCAl carriers were diagnosed with breast cancer shortly after PGD treatment, despite negative screening prior to PGD.

\section{Conclusions}

PGD for HBOC proved to be suitable, yielding good pregnancy rates for asymptomatic carriers as well as breast cancer survivors. Because of two cases of breast cancer shortly after treatment, maternal safety of IVF(/PGD) in female carriers needs further evaluation. 


\section{Abbreviations}

PGD, preimplantation genetic diagnosis

HBOC, hereditary breast and ovarian cancer

IVF, in vitro fertilisation

ICSI, intracytoplasmic sperm injection

BMI, body mass index

MRI, magnetic resonance imaging

PCR, polymerase chain reaction

FET, frozen/thawed embryo transfer cycle 


\section{Keywords}

Preimplantation genetic diagnosis, hereditary breast and ovarian cancer, BRCA1, BRCA2, reproductive outcome 


\section{Purpose}

Hereditary breast and ovarian cancer (HBOC) is an autosomal dominant cancer predisposition syndrome caused by mutations in tumor suppressor genes Breast Cancer 1 (BRCA1, 17q21.31, MIM 113705) or Breast Cancer 2 (BRCA2, 13q13.1, MIM 600185). Female carriers have strongly increased risks for both breast and ovarian cancer, estimated at $57 \%$ and $49 \%$ for breast cancer and $40 \%$ and $18 \%$ for ovarian cancer for $B R C A 1$ and $B R C A 2$ respectively, at the age of 70 [1]. In comparison, women in the United Kingdom in general have a $12.5 \%$ lifetime risk for invasive breast cancer and $1.9 \%$ for invasive ovarian cancer [2,3]. The prevalence of germline $B R C A 1 / 2$ mutations is estimated at $0.1-1.0 \%$ in the general population, making HBOC one of the more prevalent autosomal dominant genetic disorders $[4,5]$.

Carriers of a BRCA1/2 mutation have a $50 \%$ risk of passing this predisposition to their offspring. There are several reproductive options to circumvent this, but only two lead to a child genetically related to both partners: prenatal diagnosis and preimplantation genetic diagnosis (PGD). Prenatal diagnosis on the one hand, involves genetic testing of a fetus for the presence of a familial BRCA1/2 mutation during pregnancy, followed by pregnancy termination in case of an unfavourable result. Although applied on a small scale, reports regarding clinical experience with prenatal diagnosis for $\mathrm{HBOC}$ are not available in the literature to date. Preimplantation genetic diagnosis (PGD) on the other hand, involves in vitro fertilisation (IVF) with intracytoplasmic sperm injection (ICSI), followed by genetic testing of the embryos for the presence of a familial BRCA1/2 mutation before intrauterine transfer. PGD has been successfully applied since 1990 for an expanding list of monogenic disorders and chromosomal abnormalities [6]. In 2003, the Ethics Taskforce of the European Society of Human Reproduction and Embryology stated that it is acceptable to perform PGD for late onset and multifactorial diseases, including HBOC [7]. In 2005, a survey among BRCA1/2 carriers was carried out to investigate the public attitude towards PGD for HBOC, an 
important step in the legalization of PGD for hereditary cancer syndromes in the United Kingdom [8,9]. This study and other opinion surveys have shown that most BRCA carriers consider PGD for HBOC as an acceptable reproductive option, although only a minority of them would consider using PGD personally $[9,10]$. However, appliance of both prenatal diagnosis as well as PGD for HBOC remains controversial, considering the reduced penetrance of the condition, its late onset, and availability of prophylactic and therapeutic options [11]. Previous research has shown that safety of ovarian stimulation for IVF is an important consideration for female BRCA carriers when deciding on PGD [12]. This topic has not extensively been studied in female $B R C A 1 / 2$ carriers to date, although one case-control study did not find a significant adverse effect on the incidence of breast cancer [13]. Up to now, some case-reports and small case-series have been reported on the clinical experience with PGD for HBOC, with Jasper and colleagues as the first to report a pregnancy in 2008 [14-18].

In 2006 PGD for HBOC was started at the Universitair Ziekenhuis Brussel, Belgium (hereafter named centre A) and in 2008 at Maastricht University Medical Centre +, the Netherlands (hereafter centre B), two large centres for PGD in Western Europe [19]. In this study we aim to determine suitability of this treatment, for both asymptomatic male and female $B R C A 1 / 2$ carriers as well as $B R C A$-positive female breast cancer survivors, in terms of genetic results, pregnancy rates, and successful deliveries. Additionally, we report on cancer outcome of female mutation carriers.

\section{Methods}

\section{Patients}

Observational cohort study on PGD cycles performed for BRCA1/2 mutations from the onset in 2006 until 1-1-2012. Couples of whom at least one partner was known to have a $B R C A 1 / 2$ 
mutation were referred for PGD counseling to our centres. We provided them with verbal and written information regarding the PGD procedure (including IVF and ICSI, embryo biopsy, single cell analysis, chance of pregnancy, and risk of misdiagnosis). We considered female age $>40$ years and female body mass index $(\mathrm{BMI})>30 \mathrm{~kg} / \mathrm{m}^{2}$ as relative contra-indications for PGD, whereas female age $\geq 43$ years and female BMI $\geq 35 \mathrm{~kg} / \mathrm{m}^{2}$ were absolute contraindications.

\section{Gynaecological screening procedures}

We performed gynaecological and andrological examination, including sperm analysis, female hormonal assessment, and virology tests of both partners, to ensure suitability of the couple for IVF/ICSI treatment. In cases where embryos were harvested by IVF/ICSI prior to chemotherapy, appliance of PGD on these cryopreserved embryos was possible.

\section{Oncological screening procedures}

We screened female carriers without a prophylactic mastectomy in the past for the presence of occult breast cancer before admission to the PGD program. In addition to annual screening procedures, at least a magnetic resonance imaging (MRI) of the breasts was performed prior to the start of PGD [20,21]. BRCA-positive women with a history of breast cancer were eligible for PGD if they had been free of malignant disease for at least two years after their oncologic treatment. Depending on age and familial phenotype, we screened female carriers for the presence of occult ovarian carcinoma prior to admission to the PGD program by gynaecological and ultrasound examination and CA-125 determination in blood.

PGD procedures 
Prior to the introduction of the PGD program, we obtained medical ethical approval of the institutional review boards at both centres. All couples gave their informed consent before PGD was started. We performed IVF and PGD according to international guidelines [22,23] and used ICSI for fertilisation to avoid contamination of the zona pellucida with spermatozoa, which may disturb the PGD analysis. We biopsied obtained embryos three days after fertilisation. Single cell analysis of the blastomeres was performed using polymerase chain reaction (PCR), based on haplotyping of at least two informative flanking microsatellite markers on each side of the $B R C A 1 / 2$ loci. In a minority of cases this generic test was not informative. In these cases we set up a mutation specific protocol, based on identifying the private mutation in combination with at least one informative marker (table 1) $[15,24]$. After single cell analysis we classified the embryos as affected (BRCA1/2 mutation present), unaffected (BRCA1/2 mutation absent), abnormal (abnormal genotype, e.g. haploidy or triploidy) or no diagnosis (no test result or inconclusive BRCA1/2 status). Subsequently, one or two unaffected embryos were transferred into the uterus at day four or five postfertilisation. The number of transferred embryos depended on embryo quality, female age, number of previous unsuccessful attempts, and the couples' preference for transferring only one embryo. Supernumerary unaffected embryos of sufficient quality were cryopreserved and transferred in a subsequent cycle after thawing (defined as 'frozen/thawed embryo transfer cycle, FET') [25]. FETs were included in the survey if they followed a fresh IVF/PGD cycle during the study period and in case the embryo transfer was performed before 1-10-2012.

Pregnancy rates are reported as positive hCG tests as well as clinical pregnancy rates. The clinical pregnancy rate was diagnosed according to the standard definition, i.e. a pregnancy diagnosed by transvaginal ultrasonographic visualization of one or more gestational sacs or definite clinical signs of pregnancy, including ectopic pregnancy. A delivery was defined as the birth of one or more fetuses after at least 20 completed weeks of gestational age [25]. 
Couples were given the option of prenatal diagnosis to confirm PGD outcome. Follow-up of pregnancies and children was carried out at centre A as described earlier [26] and at centre B using a questionnaire. At the end of the study time (i.e. 1-10-2012) all female $B R C A 1 / 2$ carriers were contacted by telephone and asked for their health status, including diagnosis of breast cancer since the last PGD treatment and prophylactic surgeries performed in the meantime.

\section{Statistical analysis}

Statistical analyses were performed using SPSS 18.0.0. Data are presented as mean and standard deviation (for continuous variables) or number of cases and percentages (for categorical variables).

\section{Results}

\section{Patients}

70 couples underwent PGD for HBOC. In one couple the male and female partner were both a BRCA1 carrier. Of 71 carriers, 42 were female (59.2\%). Of the female carriers, $28(66.7 \%)$ had a BRCA1 mutation and fourteen (33.3\%) a BRCA2 mutation. Of 29 male carriers, 21 (72.4\%) had a BRCA1 mutation and eight $(27.6 \%)$ a BRCA2 mutation. Over a quarter of female carriers $(11 / 42,26.2 \%)$ had undergone prophylactic breast surgery before PGD. Six out of 42 female carriers $(14.3 \%$ ) had a history of breast cancer (table 2).

\section{Outcome}

In total, 145 PGD cycles were carried out (table 3 ). Three of these cycles involved PGD on embryos cryopreserved before chemotherapy because of breast cancer. Overall, 720 embryos were tested for $B R C A 1 / 2$, identifying $294(40.8 \%)$ as unaffected, $311(43.2 \%)$ as affected, 70 
(9.7\%) as abnormal, and $45(6.3 \%)$ as having no diagnosis. In 87 out of 142 fresh IVF/PGD cycles $(61.3 \%)$ one or two embryos were transferred, resulting in 37 positive hCG tests and 34 clinical pregnancies. Clinical pregnancy rates were $23.9 \%$ per cycle started and $39.1 \%$ per embryo transfer. Subsequently to these fresh IVF/PGD cycles, 34 frozen/thawed embryo transfer cycles (FETs) were performed, resulting in 10 positive hCG tests and 9 clinical pregnancies (clinical pregnancy rate $26.5 \%$ per embryo transfer, table 3 ).

Three out of six women with a history of breast cancer had harvested embryos prior to chemotherapy and underwent PGD on these embryos. Two of them delivered a healthy child after PGD. Subsequently, two of these three women were denied a fresh ovarian stimulation for PGD because of a diminished ovarian reserve after chemotherapy. The third woman, and the three women who did not cryopreserve embryos, were treated in one or more fresh IVF/PGD cycles. One of them delivered a healthy child (table 4).

In centre $\mathrm{A}$, four couples pregnant after $\mathrm{PGD}$ for $B R C A 1$ requested prenatal diagnosis to confirm PGD diagnosis. In two cases a chorionic villus biopsy was performed (one in a twin pregnancy), amniocentesis in the other two. All results were BRCA-negative, confirming PGD outcome. None of the pregnant couples treated in centre B opted for prenatal diagnosis to confirm PGD diagnosis.

Out of a total of 45 clinical pregnancies, $36(80.0 \%)$ proceeded to birth. The other 9 resulted in a miscarriage or concerned ectopic pregnancies. Of 41 children (31 singletons and five twins), $38(92.7 \%)$ were born alive. One singleton pregnancy was terminated at 23 weeks of gestation because of multiple congenital malformations based on a de novo chromosomal abnormality (deletion 3q26.2 and duplication 15q11.2). Two other children were stillborn: one member of twins died in utero at 24 weeks of gestation for unknown reasons; the other sibling was born alive at 33 weeks. One member of another twin died in utero due to abruption of the placenta at 35 weeks of gestation. The other sibling was born alive. One 
singleton pregnancy was complicated by premature labour at 26 weeks of gestation. At the end of study time, at age 2.5 years, the girl born was doing well.

\section{Follow-up of female BRCA1/2 carriers}

Two BRCAl carriers (one in each PGD centre) were diagnosed with early stage triple negative breast cancer within two, respectively three months after their first ovarian stimulation for IVF/PGD, despite having a negative breast screening shortly before (table 5). One of them had a history of contralateral breast cancer. Both women did not become pregnant after PGD.

One female carrier did not want to be contacted to check on her medical condition after PGD for personal reasons; all other female carriers were contacted. None of them have been diagnosed with breast cancer after PGD. Mean exposed follow-up time (from ovarian stimulation until end of follow-up or until prophylactic breast surgery) was 27.5 months (range 2 to 68 months).

\section{Conclusions}

This study establishes the clinical suitability of PGD for $B R C A 1 / 2$ mutations in both asymptomatic carriers and BRCA-positive female breast cancer survivors, either in a fresh IVF/PGD cycle as well as on embryos harvested before chemotherapy. A series of 145 consecutive PGD cycles is presented, the first large series of PGD for HBOC. When compared to the outcome of PGD for autosomal dominant disorders as reported by the European Society of Human Reproduction and Embryology PGD consortium, our clinical pregnancy rates are in line with these data (39.1\% vs. $26.7 \%$ per embryo transfer respectively) [6]. Two factors known to influence reproductive outcome in $B R C A 1 / 2$ carriers were present in our series: on the one hand, the women included in our survey were younger than those 
reported by the PGD consortium (29.6 versus 34 years), which is a favourable factor for reproductive outcome. On the other hand, it was hypothesized that $B R C A 1 / 2$ mutations may unfavourably reduce ovarian reserve due to accumulated DNA damage secondary to inadequate DNA repair [27]. In total, 49 pregnancies were established, resulting in the birth of 31 singletons and five twins. The observation of two perinatal deaths and one pregnancy termination because of major malformations in our cohort of 41 children is presumed to be an coincidence; PGD is not associated with an increased risk for perinatal deaths or major congenital malformations [26]. However, the health of children born after PGD (for HBOC) needs to be subject to further research and longer follow-up.

Analysis of the blastomeres for the presence of $B R C A 1 / 2$ reflected the suspected 50/50 distribution of unaffected (41\%) versus affected (43\%) embryos. Almost $10 \%$ of the embryos showed fertilisation abnormalities (e.g. haploidy or triploidy), which is not an uncommon finding in preimplantation embryos. We presume that the diagnostic accuracy of PGD analyses based on PCR is high; an earlier study in one of our centres reported a false-negative rate of $0.5 \%$ in surplus embryos [28]. This is in accordance to the reported misdiagnosis rate of $0.4 \%$ in pregnancies established after PGD for monogenic disorders detected by PCR analysis [29]. However, since only few of the pregnant couples opted for prenatal diagnosis, definitive confirmation of PGD diagnosis was not possible in the majority of cases. Because genetic testing for adult-onset disorders in childhood is ethically controversial and therefore discouraged [30], postnatal testing after PGD for HBOC was not performed.

In addition to the suitability of PGD for HBOC following a fresh IVF/PGD cycle, we also demonstrated that PGD on embryos harvested prior to chemotherapy is an applicable option: two out of three women treated, delivered a healthy child. These results stress the importance of timely counseling regarding fertility preserving options available for young women with breast cancer [31,32]. This is important not only to retain an option to reproduce in case 
oncological treatment would cause infertility, but also because PGD can be applied on harvested embryos in case of $B R C A$ carriership. Known $B R C A$ status at the moment of fertility preservation is not a prerequisite, provided that ICSI is used for fertilisation to keep the possibility of PCR analysis. When cryopreserved embryos of sufficient quality are available, it is preferable to use these first for PGD. This can save the patient a new ovarian stimulation, which may be less successful in case of a diminished ovarian reserve after oncological treatment.

Two women in our cohort were diagnosed with breast cancer after their first IVF/PGD cycle. One of these women had a history of contralateral breast cancer. Both women were carrier of a BRCA1 mutation. BRCAl-associated tumors are characterized by a higher proportion of interval tumors and a younger age and more often an unfavourable size at diagnosis, when compared with BRCA2-associated tumors. Besides, invasive BRCA1 breast tumors are often high grade and rapidly growing [33,34]. While a possible linkage between IVF treatment and breast cancer risk has extensively been studied in the general population [35], safety of IVF with regards to the risk for breast cancer has not been systematically studied in female BRCA1/2 carriers. Gonadotropin use for IVF results in a rise in estrogens. Several observations suggest an influence of (prolonged) exposure to estrogens on incidence of $B R C A$-related breast cancers, although approximately $80 \%$ of $B R C A 1$-tumors are estrogen and progesterone receptor negative [36]. Kotsopoulos and colleagues conducted a matched casecontrol study to examine the influence of fertility medications for IVF treatment on breast cancer risk in $B R C A 1 / 2$ carriers. They were able to include 26 carriers with a history of gonadotropin use, sixteen of whom were diagnosed with breast cancer (multivariate OR 2.32, $95 \%$ CI $0.91-5.95, \mathrm{p}=0.08)$. The sample size of the study may have been too limited however to detect a significant adverse effect of gonadotropin use on breast cancer risk in $B R C A 1 / 2$ carriers [13]. One study reported an association between fertility treatment and an increased 
risk for breast cancer in women with a positive family history for breast cancer (RR $1.4 ; 95 \%$ CI 1.0-1.9) [37], while others did not find fertility (treatment) and breast cancer to be associated in these women [38,39]. It is possible, yet unproven that administering gonadotropins may have led to an acceleration in growth of pre-existing, but not yet detectable, tumors in the two affected BRCAl carriers in our cohort. Therefore we stress the importance of screening of the breasts before admission to IVF(/PGD) treatment, as well as after treatments. Larger studies are needed to elucidate whether our observation is just a coincidental finding in a population with a high a priori risk for breast cancer, or whether a causal relationship exists.

This study has some limitations. Firstly, the sample size is relatively small. Secondly, reliability of PGD diagnosis could not be confirmed; it was ethically impossible to test $B R C A$ status of the children born after PGD, due to the late onset character of the predisposition and the children's autonomy. Finally, our study was not primarily designed to assess maternal safety of IVF in female carriers.

\section{Recommendations}

This survey shows that PGD for HBOC is an established and suitable technique with good reproductive outcome, which should be offered as part of a comprehensive approach to the counseling and treatment of all BRCA1/2 patients. It is important that medical professionals involved in the care for $B R C A$ carriers are aware of this reproductive option, in order to inform patients timely and to refer them, at request, to a specialized PGD centre. In case of a newly diagnosed breast cancer in a woman of reproductive age, it is essential to be aware of the possibility of PGD if and when BRCA carriership would turn out. Given the complex medical history of female carriers and our observation of two breast cancer cases after PGD treatment, a multidisciplinary approach is a prerequisite in PGD practice. In addition, 
oncological screening of female carriers before admission to the treatment, as well as careful follow-up, is required.

\section{Acknowledgements}

This study was financially supported by a personal grant for IDS, kindly provided by the Dutch Cancer Society (grant number UM 2011-5249). We thank our colleagues of the Universitair Ziekenhuis Brussel, Belgium, and the Dutch collaboration for PGD in the Netherlands "PGD Nederland" for their contributions, in particular professor I. Liebaers (Universitair Ziekenhuis Brussel), professor H. Evers, E. Gomez Garcia, Y. Arens (all Maastricht University Medical Centre+), professor Broekmans, L. Page-Christiaens (both University Medical Centre Utrecht), professor C. van Ravenswaaij-Arts, and professor J. Land (both University Medical Centre Groningen), who were involved in the counselling and recruitment of patients and determination of the couples' suitability for IVF/PGD. We thank A. de Vos (Universitair Ziekenhuis Brussel) and E. Coonen and J. Derhaag (both Maastricht University Medical Centre+) for their involvement in the embryo biopsies. Professor K. Sermon and professor C. Spits (both Universitair Ziekenhuis Brussel) were involved in the development of the PGD-PCR tests for HBOC. W. Meul (Universitair Ziekenhuis Brussel) and N. Muntjewerff (Maastricht University Medical Centre+) were involved in datacollection. A. Buysse, L. Ausloos (both Universitair Ziekenhuis Brussel), and M. van Deursen-Luijten (Maastricht University Medical Centre+) contributed to the children followup.

\section{Ethical statement}

This study complies with current laws in the Netherlands and Belgium. Medical ethical approval of the institutional review boards was obtained before the start of PGD at both 
centres. Participants gave their informed consent before they were enrolled in the program.

\section{Conflict of interest}

The authors declare that they have no conflict of interest. 


\section{References}

1. Chen S, Parmigiani G (2007) Meta-analysis of BRCA1 and BRCA2 penetrance. J Clin Oncol 25(11):1329-33

2. Cancer Research UK: Breast cancer incidence statistics.

http://www.cancerresearchuk.org/cancer-info/cancerstats/types/breast/incidence/uk-breastcancer-incidence-statistics. Accessed 27 February 2014

3. Cancer Research UK: Ovarian cancer incidence statistics.

http://www.cancerresearchuk.org/cancer-info/cancerstats/types/ovary/incidence/. Accessed 27 February 2014

4. Ford D, Easton DF, Peto J (1995) Estimates of the gene frequency of BRCA1 and its contribution to breast and ovarian cancer incidence. Am J Hum Genet 57(6):1457-62

5. Risch HA, McLaughlin JR, Cole DE, Rosen B, Bradley L, Fan I, et al (2006) Population BRCA1 and BRCA2 mutation frequencies and cancer penetrances: a kin-cohort study in Ontario, Canada. J Natl Cancer Inst 98(23):1694-706

6. Goossens V, Traeger-Synodinos J, Coonen E, De Rycke M, Moutou C, Pehlivan T, et al (2012) ESHRE PGD Consortium data collection XI: cycles from January to December 2008 with pregnancy follow-up to October 2009. Hum Reprod 27(7):1887-911

7. Shenfield F, Pennings G, Devroey P, Sureau C, Tarlatzis B, Cohen J (2003) Taskforce 5: preimplantation genetic diagnosis. Hum Reprod 18(3):649-51

8. Tilstone C (2005) UK clinicians to screen embryos for BRCA mutations. Lancet Oncol 6(6):358

9. Menon U, Harper J, Sharma A, Fraser L, Burnell M, ElMasry K, et al (2007) Views of BRCA gene mutation carriers on preimplantation genetic diagnosis as a reproductive option for hereditary breast and ovarian cancer. Hum Reprod 22(6):1573-7 
10. Staton AD, Kurian AW, Cobb K, Mills MA, Ford JM (2008) Cancer risk reduction and reproductive concerns in female BRCA1/2 mutation carriers. Fam Cancer 7(2):179-86 11. Offit K, Kohut K, Clagett B, Wadsworth EA, Lafaro KJ, Cummings S, et al (2006) Cancer genetic testing and assisted reproduction. J Clin Oncol 24(29):4775-81

12. Dekeuwer C, Bateman S (2013) Much more than a gene: hereditary breast and ovarian cancer, reproductive choices and family life. Med Health Care Philos 16:231-44

13. Kotsopoulos J, Librach CL, Lubinski J, Gronwald J, Kim-Sing C, Ghadirian P, et al (2008) Infertility, treatment of infertility, and the risk of breast cancer among women with BRCA1 and BRCA2 mutations: a case-control study. Cancer Causes Control 19(10):1111-9 14. Jasper MJ, Liebelt J, Hussey ND (2008) Preimplantation genetic diagnosis for BRCA1 exon 13 duplication mutation using linked polymorphic markers resulting in a live birth. Prenat Diagn 28(4):292-8

15. Spits C, De Rycke M, Van Ranst N, Verpoest W, Lissens W, Van Steirteghem A, et al (2007) Preimplantation genetic diagnosis for cancer predisposition syndromes. Prenat Diagn 27(5):447-56

16. Sagi M, Weinberg N, Eilat A, Aizenman E, Werner M, Girsh E, et al (2009) Preimplantation genetic diagnosis for BRCA1/2 - a novel clinical experience. Prenat Diagn 29(5):508-13

17. Tung N (2011) Management of women with BRCA mutations: a 41-year-old woman with a BRCA mutation and a recent history of breast cancer. JAMA 305(21):2211-20

18. Ramon YCT, Polo A, Martinez O, Gimenez C, Arjona C, Llort G, et al (2012) Preimplantation genetic diagnosis for inherited breast cancer: first clinical application and live birth in Spain. Fam Cancer 11(2):175-9

19. Sheldon T (2008) Netherlands debates screening for breast cancer. BMJ 336(7656): 1270 
20. Integraal Kankercentrum Nederland, Nationaal Borstkanker Overleg Nederland: Breast cancer, Dutch guideline, version 2.0. http://www.oncoline.nl/breastcancer. Accessed 27 February 2014

21. Warner E, Hill K, Causer P, Plewes D, Jong R, Yaffe M, et al (2011) Prospective study of breast cancer incidence in women with a $B R C A 1$ or $B R C A 2$ mutation under surveillance with and without Magnetic Resonance Imaging. J Clin Oncol 29(13):1664-9 22. Magli MC, Van den Abbeel E, Lundin K, Royere D, Van der Elst J, Gianaroli L; Committee of the Special Interest Group on Embryology (2008) Revised guidelines for good practice in IVF laboratories. Hum Reprod 23(6):1253-62

23. Harton G, Braude P, Lashwood A, Schmutzler A, Traeger-Synodinos J, Wilton L, et al (2011) ESHRE PGD consortium best practice guidelines for organization of a PGD centre for PGD/preimplantation genetic screening. Hum Reprod 26(1):14-24

24. Drüsedau M, Dreesen JC, Derks-Smeets I, Coonen E, Van Golde R, van EchtenArends J, et al (2013) PGD for hereditary breast and ovarian cancer: the route to universal tests for BRCA1 and BRCA2 mutation carriers. Eur J Hum Genet 21(12):1361-8

25. Zegers-Hochschild F, Adamson GD, de Mouzon J, Ishihara O, Mansour R, Nygren K, et al (2009) International Committee for Monitoring Assisted Reproductive Technology (ICMART) and the World Health Organization (WHO) revised glossary of ART terminology, 2009. Fertil Steril 92(5):1520-4

26. Desmyttere S, De Rycke M, Staessen C, Liebaers I, De Schrijver F, Verpoest W, et al (2012) Neonatal follow-up of 995 consecutively born children after embryo biopsy for PGD. Hum Reprod 27(1):288-93

27. Oktay K, Kim JY, Barad D, Babayev SN (2010) Association of BRCA1 mutations with occult primary ovarian insufficiency: a possible explanation for the link between infertility and breast/ovarian cancer risks. J Clin Oncol 28(2):240-4 
28. Dreesen J, Drusedau M, Smeets H, de Die-Smulders C, Coonen E, Dumoulin J, et al (2008) Validation of preimplantation genetic diagnosis by PCR analysis: genotype comparison of the blastomere and corresponding embryo, implications for clinical practice. Mol Human Reprod 14(10):573-9

29. Wilton L, Thornhill A, Traeger-Synodinos J, Sermon KD, Harper JC (2009) The causes of misdiagnosis and adverse outcomes in PGD. Hum Reprod 24(5):1221-8

30. Borry P, Evers-Kiebooms G, Cornel MC, Clarke A, Dierickx K (2009) Genetic testing in asymptomatic minors: background considerations towards ESHG Recommendations. Eur J Hum Genet 17(6):711-9

31. Rodriguez-Wallberg KA, Oktay K (2012) Fertility preservation and pregnancy in women with and without BRCA mutation-positive breast cancer. Oncologist 17(11):1409-17 32. Peate M, Meiser B, Friedlander M, Zorbas H, Rovelli S, Sansom-Daly U, et al (2011) It's now or never: Fertility-related knowledge, decision-making preferences, and treatment intentions in young women with breast cancer - an Australian fertility decision aid collaborative group study. J Clin Oncol 29(13):1670-7

33. Rijnsburger AJ, Obdeijn IM, Kaas R, Tilanus-Linthorst MM, Boetes C, Loo CE, et al (2010) BRCA1-associated breast cancers present differently from BRCA2-associated and familial cases: long-term follow-up of the Dutch MRISC Screening Study. J Clin Oncol 28(36):5265-73

34. Atchley DP, Albarracin CT, Lopez A, Valero V, Amos CI, Gonzalez-Angulo AM, et al (2008) Clinical and pathologic characteristics of patients with $B R C A$-positive and $B R C A$ negative breast cancer. J Clin Oncol 26(26):4282-8

35. Zreik TG, Mazloom A, Chen Y, Vannucci M, Pinnix CC, Fulton S, et al (2010) Fertility drugs and the risk of breast cancer: a meta-analysis and review. Breast Cancer Res Treat 124(1):13-26 
36. Narod SA (2006) Modifiers of risk of hereditary breast cancer. Oncogene 25(43):5832-6

37. Gauthier E, Paoletti X, Clavel-Chapelon F (2004) Breast cancer risk associated with being treated for infertility: results from the French E3N cohort study. Hum Reprod 19(10):2216-21

38. Braga C, Negri E, La Vecchia C, Parazzini F, Dal Maso L, Franceschi S (1996)

Fertility treatment and risk of breast cancer. Hum Reprod 11(2):300-3

39. Grabrick DM, Vierkant RA, Anderson KE, Cerhan JR, Anderson VE, Seller TA

(2002) Association of correlates of endogenous hormonal exposure with breast cancer risk in 426 families (United States). Cancer Causes Control 13(4):333-41 
Table 1: PGD strategies for $B R C A 1 / 2$ mutations

\begin{tabular}{|c|c|c|}
\hline & Centre $\mathbf{A}^{\mathrm{a}}$ & Centre $^{\text {b }}$ \\
\hline Indirect testing $B R C A 1$ mutations $^{\mathrm{c}}$ & $\begin{array}{l}\text { BRCA1STR24CA, BRCA1STR20TG, } \\
\text { BRCA1STR16GA, BRCA1STR4, } \\
\text { BRCA1STR21CA, D17S2249, D17S1323, } \\
\text { D17S855 }\end{array}$ & $\begin{array}{l}\text { D17S932, BRCA1_dis24AC, D17S950, } \\
\text { D17S1814, D17S800, D17S1787 }\end{array}$ \\
\hline Indirect testing $B R C A 2$ mutations $^{\mathrm{c}}$ & $\begin{array}{l}\text { BRCA2STR19TG, BRCA2STR20GT, } \\
\text { BRCA2STR18AC, D13S260, D13S171 }\end{array}$ & $\begin{array}{l}\text { D13S171, D13S1695, BRCA2_dist18AC, } \\
\text { D13S267, D13S289, D13S260, D13S1698, } \\
\text { BRCA2STR19 }\end{array}$ \\
\hline Alkaline lysis buffer & $50 \mathrm{mM}$ DTT, $200 \mathrm{mM} \mathrm{NaOH}$ & $50 \mathrm{mM}$ DTT, $200 \mathrm{mM} \mathrm{NaOH}$ \\
\hline Freezing post tubing & $30^{\prime}-20^{\circ}$ & $30^{\prime}-20^{\circ} \mathrm{C}$ \\
\hline Decontamination & UV-C & UV-C \\
\hline Polymerase & Qiagen Multiplex PCR KIT & Qiagen Multiplex PCR KIT \\
\hline Split for multiplex PCR & No & No \\
\hline Genetic analyser & ABI3730xl & ABI3730xl \\
\hline
\end{tabular}

Abbreviations: PGD, preimplantation genetic diagnosis, $B R C A 1$, breast cancer gene 1, BRCA2, breast cancer gene 2, PCR, polymerase chain reaction

a Universitair Ziekenhuis Brussel, Belgium

${ }^{\mathrm{b}}$ Maastricht University Medical Centre +, the Netherlands

${ }^{\mathrm{c}}$ Many of the markers have not been published; the primer sequences were designed in-house and are available upon request. In case indirect testing was not possible due to either non-informativity of markers or availability of family members, mutation-specific tests were developed including the typical familial mutation combined with at least 2 markers 
Table 2: Couples' characteristics

\begin{tabular}{|l|l|}
\hline & $\mathbf{n}=\mathbf{7 0}$ \\
\hline Nulliparity prior to PGD & $60(85.7 \%)$ \\
\hline At-risk person & \\
Male & $28(40.0 \%)$ \\
Female & $41(58.6 \%)$ \\
Both partners & $1^{\mathrm{a}}(1.4 \%)$ \\
\hline Mutation & \\
BRCA1 & $48(68.6 \%)$ \\
BRCA2 & $22(31.4 \%)$ \\
\hline Mean female age in years (SD) & $29.5(3.6)$ \\
Female carriers & $29.6(3.7)$ \\
\hline Mean female BMI (SD) & $23.1(3.4)$ \\
\hline Female carriers with prophylactic mastectomy & $11(26.2 \%)$ \\
\hline Female carriers with history of breast cancer & $6(14.3 \%)$ \\
\hline
\end{tabular}

Abbreviations: PGD, preimplantation genetic diagnosis, $B R C A 1$, breast cancer gene $1, B R C A 2$, breast cancer gene 2, SD, standard deviation, BMI, Body Mass Index $\left(\mathrm{kg} / \mathrm{m}^{2}\right)$

${ }^{a}$ Both partners were $B R C A 1$ carrier, only unaffected embryos were eligible for embryo transfer 
Table 3: Reproductive outcome of PGD for HBOC ( $n=70$ couples)

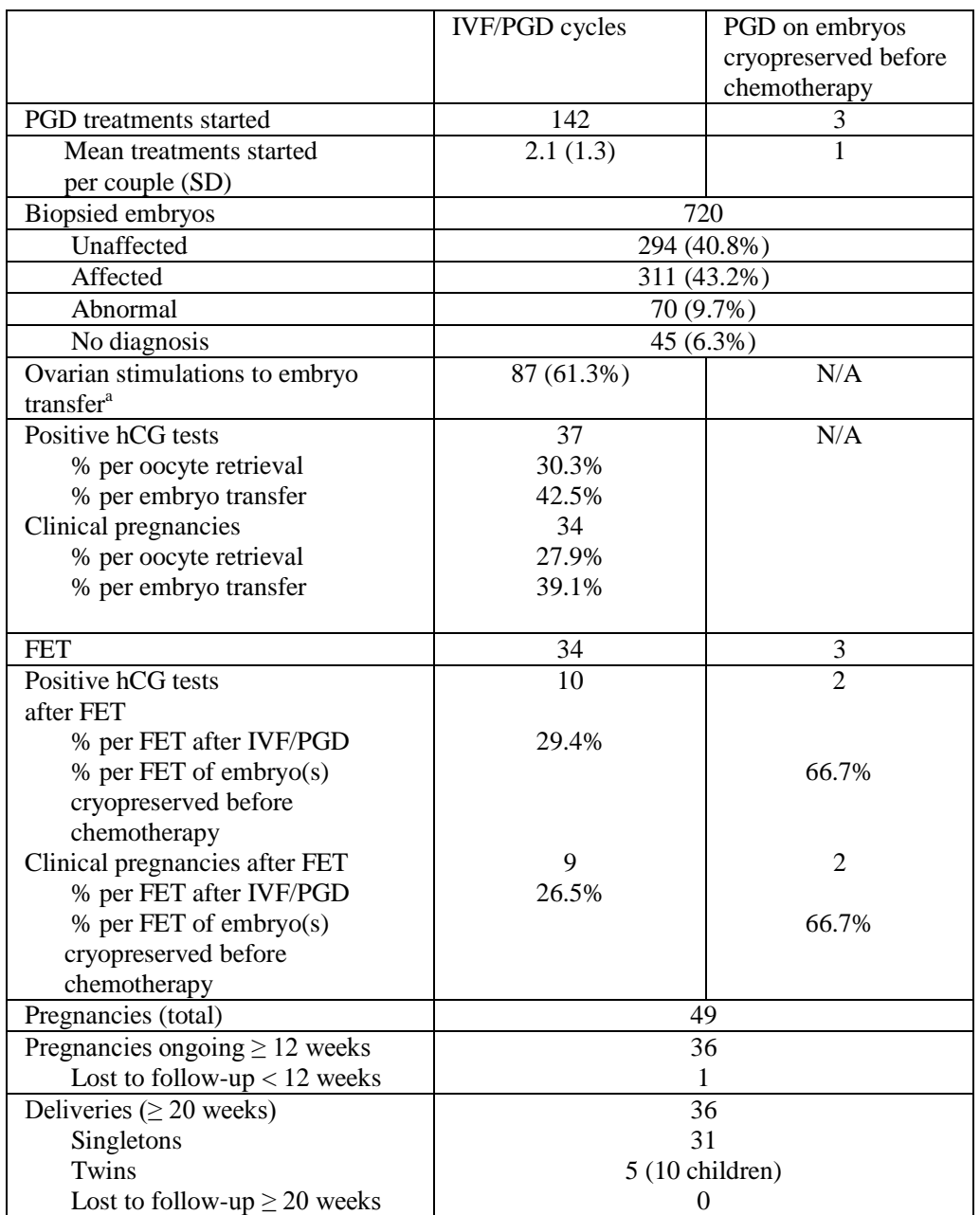

PGD, preimplantation genetic diagnosis, HBOC, hereditary breast and ovarian cancer, IVF, in vitro fertilisation, $\mathrm{SD}$, standard deviation, hCG, human chorionic gonadotropin, FET, frozen/thawed embryo transfer cycle, N/A, not applicable

a One couple, who underwent two IVF/PGD cycles, requested cryopreservation of unaffected embryos because of prophylactic salpingo-oophorectomy. In five other IVF/PGD cycles unaffected embryos were cryopreserved to postpone embryo transfer for different reasons (ovarian hyperstimulation syndrome $(n=2)$, insufficient endometrial buildup $(n=2)$, and delay of PGD results $(n=1)$ 
Table 4: Characteristics of women with a history of breast cancer before PGD treatment

\begin{tabular}{|c|c|c|c|c|c|c|}
\hline & \multicolumn{3}{|l|}{ Centre $\mathrm{A}^{\mathrm{a}}$} & \multicolumn{3}{|l|}{ Centre $\mathrm{B}^{\mathrm{b}}$} \\
\hline & Patient $\mathrm{A}^{\mathrm{c}}$ & Patient B & Patient C & Patient D & Patient E & Patient $\mathrm{F}$ \\
\hline Reproductive history & None & None & None & None & $\begin{array}{l}2005 \text { healthy daughter, } \\
2007 \text { miscarriage, } 2007 \\
\text { molar pregnancy }\end{array}$ & None \\
\hline Gynaecologic history & None & None & None & $\begin{array}{l}2007 \text { unilateral salpingo- } \\
\text { oophorectomy } \\
\text { (inflammation) }\end{array}$ & $\begin{array}{l}2007 \text { dilatation and } \\
\text { curettage }\end{array}$ & None \\
\hline Gene mutation & BRCAl & BRCAl & BRCAl & $B R C A 2$ & BRCAl & $B R C A 2$ \\
\hline Age at breast cancer diagnosis & 31 & 29 & 26 & 33 & 33 & 32 \\
\hline $\begin{array}{l}\text { Oncologic treatment } \\
\text { Surgery }\end{array}$ & Mastectomy & Mastectomy & Skin sparing mastectomy & Mastectomy & Modified radical & Lumpectomy \\
\hline Chemotherapy & Yes & Yes & Yes & Yes & Yes & No \\
\hline Irradiation & No & Yes & Yes & No & Yes & Yes \\
\hline Contralateral prophylactic mastectomy & No & Yes & Yes & Yes & Yes & No \\
\hline $\begin{array}{l}\text { Embryos cryopreserved before } \\
\text { chemotherapy }\end{array}$ & Yes & No & Yes & Yes & Yes & N/A \\
\hline $\begin{array}{l}\text { Disease free interval before first PGD } \\
\text { cycle (yrs) }\end{array}$ & 2.5 & 4.0 & 2.0 & 3.8 & 2.8 & 4.5 \\
\hline $\begin{array}{l}\text { PGD on embryos cryopreserved before } \\
\text { chemotherapy }\end{array}$ & No & N/A & Yes & Yes & Yes & N/A \\
\hline Outcome & N/A & N/A & Healthy son born & Not pregnant & Healthy daughter born & N/A \\
\hline IVF/PGD after recovery from cancer & Yes & Yes & Yes & $\begin{array}{l}\text { No (denied because of } \\
\text { chemotherapy induced } \\
\text { infertility) }\end{array}$ & $\begin{array}{l}\text { No (denied because of } \\
\text { chemotherapy induced } \\
\text { infertility) }\end{array}$ & Yes \\
\hline Outcome & No embryo transfer & Not pregnant & Ectopic pregnancy & N/A & N/A & Healthy son bo \\
\hline
\end{tabular}

PGD, preimplantation genetic diagnosis, BRCA1, breast cancer gene 1, BRCA2, breast cancer gene 2, IVF, in vitro fertilisation, N/A, not applicable

${ }^{\text {a }}$ Universitair Ziekenhuis Brussel, Belgium

${ }^{\mathrm{b}}$ Maastricht University Medical Centre +, the Netherlands

${ }^{\mathrm{c}}$ Same patient as patient $\mathrm{G}$ in table 5 . This patient was diagnosed with breast cancer and underwent one IVF cycle prior to chemotherapy to cryopreserve embryos ( $\mathrm{n}=6$ ). After recovery, she chose for a new ovarian stimulation for IVF/PGD instead of using her cryopreserved embryos first. After IVF/PGD, she was diagnosed with contralateral breast cancer and needed chemotherapy again (see table 5). She underwent two IVF cycles to cryopreserve embryos (n=1). Besides, a laparoscopic unilateral oophorectomy took place to cryopreserve the ovary. After recovery of the second breast cancer, she conceived spontaneously and gave birth to a twin 
Table 5: Overview of women who were diagnosed with breast cancer after PGD treatment

\begin{tabular}{|c|c|c|}
\hline & Patient $\mathrm{G}^{\mathrm{a}}$ & Patient $\mathrm{H}$ \\
\hline PGD Centre & Centre $\mathrm{A}^{\mathrm{b}}$ & Centre $\mathrm{B}^{\mathrm{c}}$ \\
\hline Gene mutation & $B R C A 1$ & BRCA 1 \\
\hline Oncologic history prior to PGD & $\begin{array}{l}\text { Diagnosed with breast cancer in 2006: invasive ductal carcinoma, } \\
\text { T2mN0M0, triple negative. Treatment consisted of mastectomy and } \\
\text { chemotherapy }\end{array}$ & None \\
\hline $\begin{array}{l}\text { Reproductive history prior to PGD cycle after which } \\
\text { breast cancer was diagnosed }\end{array}$ & $\begin{array}{l}\text { One IVF cycle for fertility preservation prior to chemotherapy in } \\
2006 \text { ( } 6 \text { embryos). It was the patient's choice to undergo a new } \\
\text { ovarian stimulation for PGD instead of using the cryopreserved } \\
\text { embryos first }\end{array}$ & None \\
\hline Age at breast cancer diagnosis after PGD & 34 & 28 \\
\hline Last breast screening before PGD & One month before PGD, MRI: no abnormalities & Two months before PGD, MRI: no abnormalities \\
\hline Number of IVF/PGD cycles & 1 & 1 \\
\hline Outcome IVF/PGD cycle & No embryo transfer & Not pregnant \\
\hline Breast cancer diagnosis & Two months after PGD, MRI & Three months after PGD, MRI \\
\hline Pathology & Invasive ductal carcinoma, T1cN0M0, triple negative & Invasive ductal carcinoma, $\mathrm{T} 1 \mathrm{bN} 1 \mathrm{aM} 0$, triple negative \\
\hline \multicolumn{3}{|r|}{ 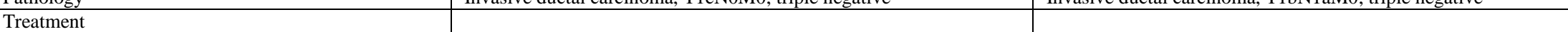 } \\
\hline Oncologic surgery & Mastectomy, SNP & Lumpectomy, axillary lymph node dissection \\
\hline Systemic therapy & Yes & Yes \\
\hline Irradiation & No & Yes \\
\hline Prophylactic mastectomy & N/A & Planned \\
\hline Current status & $\begin{array}{l}\text { No evidence of disease, delivered twin after spontaneous conception } \\
\text { (see legend table 4) }\end{array}$ & $\begin{array}{l}\text { No evidence of disease, wishes to continue PGD after recovery of } \\
\text { prophylactic surgery }\end{array}$ \\
\hline
\end{tabular}

PGD, preimplantation genetic diagnosis, BRCAl, breast cancer gene 1, IVF, in vitro fertilisation, MRI, magnetic resonance imaging, SNP, sentinel node procedure,

N/A, not applicable

${ }^{a}$ Same patient as patient $\mathrm{A}$ in table 4

${ }^{\mathrm{b}}$ Universitair Ziekenhuis Brussel, Belgium

${ }^{c}$ Maastricht University Medical Centre +, the Netherlands 